\title{
CONTANDO HISTÓRIAS E ENCANTANDO NOS ESPAÇOS DE LEITURA
}

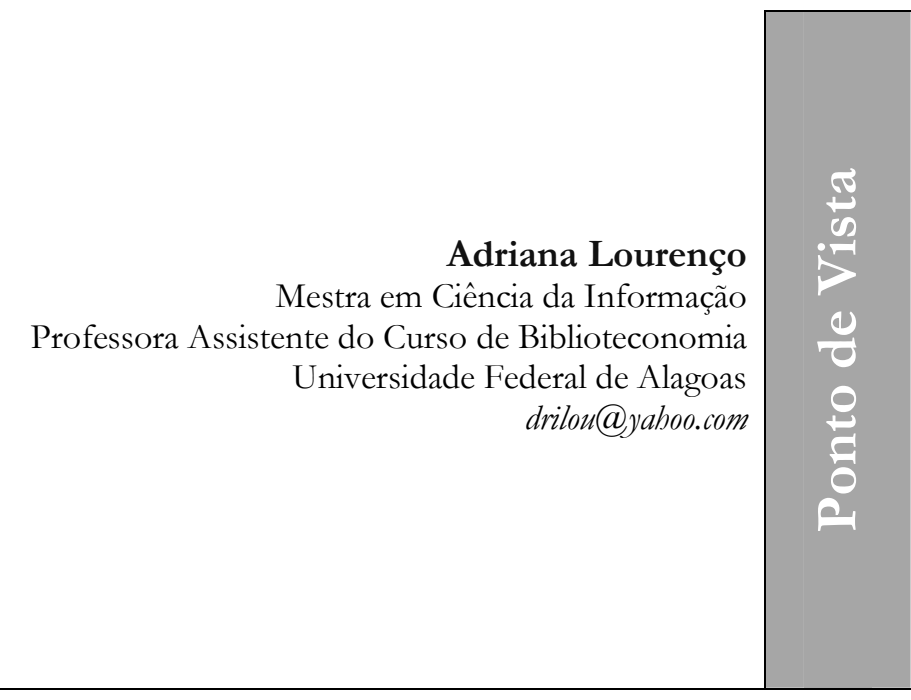

\section{Resumo}

Discorre sobre a contação de história como arte, uma experiência estética, possível de encantar sua audiência. Percorre o conceito de encantamento como um estado de êxtase, destacando que esse estado de além -consciência propicia um retorno ao "eu" do agente, ou seja, um auto-encantar-se do contador de histórias, que poderá, primeiramente, fruir desse encantamento. Reflete sobre o Plano Nacional da Biblioteca na Escola (PNBE) como um fomentador de livros que o contador de histórias pode e deve se alimentar.

\section{Palavras-chave}

Contação de histórias. Contador de histórias. Encantamento. Programa Nacional da Biblioteca na Escola (PBNE).

\section{INTRODUÇÃO}

O hábito de contar histórias é um dos poucos traços humanos presentes em todas as culturas. Alguns apontam sua origem desde a época das cavernas.

Ainda que o ato de contar histórias possa ser uma característica do evolucionismo da espécie humana, sem entrar em discussão darwinista, o que questionamos hoje é por que continuamos contando histórias. Por que o ser humano continua com essa prática? Por que recontar histórias oralmente em um mundo repleto de mídias que podem desenvolver semelhante função?
Em um ambiente tão tecnológico como o de hoje, que cerca a criança desde seu nascimento, as histórias podem ser acessadas com um simples toque em uma tela touchscreen. Então, por que ouvir uma história?

Dentre as várias possibilidades de respostas que podem ser construídas, optamos por discorrer sobre o fato de a contação de histórias, como arte, encantar a sua audiência. $\mathrm{O}$ encantamento por meio da contação de história seria a razão para continuarmos a contar e a ouvir histórias, perpetuando esse ato por gerações.

Partindo desse posicionamento, contudo, instiga-nos a reflexão de forma estruturalista: o que seria esse encantamento? 
Como a história contada encanta a sua audiência? Se a história vai encantar quem estiver ouvindo, então, aquele que a conta, que também a ouve, nesse caso o contador de histórias, deveria estar encantado da mesma maneira?

Tratam-se de questões para ampla discussão, uma vez que a expressão encantamento pode levar a pensar sobre algo mágico, algum feitiço, ou algo, pelo menos, fantástico ou inebriante, um estado de êxtase ou qualquer palavra que indique algo além da própria consciência. Esse estado de alémconsciência pode, no entanto, ser percebido como um retorno ao "eu", um "eu" que se permite enfeitiçar e enfeitiçar-se, encantar e encantar-se, um estado de explosão e mistura, de catarse.

\section{O ENCANTAMENTO CONTAÇÃO DE HISTÓRIAS}

NA

Como sugerido em Griffero (2009, p. 6), a catarse representaria a própria experiência estética no encontro do próprio eu fruindo "[...] a si na fruição do outro". O encantamento supõe uma experiência estética no próprio "eu", favorecendo uma hermenêutica. Nesse sentido, para encantar com uma história, o contador coloca-se em uma perspectiva de estar encantado e de viver essa catarse, primeiramente, em busca da sua própria fruição.

Ainda conforme Griffero (2009), o encantamento como experiência estética confirma o valor estético da obra a que se expõe. Talvez esse seja um caminho para responder o contar e recontar histórias já conhecidas e reconhecidas através de gerações, pois, por meio dessa experiência, é possível tornar perceptível, visível e audível o que não é percebido, dito e ouvido no cotidiano. Com isso, podemos ter a compreensão de que, permitindo o contador de história encantar-se, fruindo dessa experiência estética e conferindo valor estético à obra, também se pode proporcionar à audiência a possibilidade do encantamento como uma experiência estética de reencontro do seu "eu".

Desta feita, tendo a contação de histórias como uma de suas possibilidades o incentivo à leitura, uma vez se posicionando como instrumento para mediação de leitura, é necessário voltarmos o olhar para o sujeito dessa ação, o mediador da leitura, que, nesse contexto, o contador de histórias.

Esse sujeito precisa antes fruir desse encantamento para, então, colocar-se na perspectiva de proporcionar uma ação possível de levar o outro ao encantamento. Para tanto, é necessário que esse sujeito, o contador de história, coloque-se nessa perspectiva, assumindo para si esse empenho da prática de si. Trata-se de seguir as reflexões foulcoutianas, "voltar o olhar para si" e "conhecer a si mesmo", tornando-se imprescindível o cuidado de si a fim de proporcionar esse retorno ao "eu".

Em nosso contexto de reflexão, o sujeito que se coloca como mediador da leitura, utilizando-se da arte da contação de histórias, coloca-se antes de tudo na posição necessária para vivenciar a experiência estética que a história pode proporcionar, para, a partir da interpretação da história, propiciar a experiência estética na audiência. Nesse contexto, emerge a seguinte questão: e se o sujeito não tem essa vivência de experiência estética, como mediar algo desconhecido?

Para Foucault (2010), a prática de si identifica-se com a própria arte de viver, na caracterização de uma própria identidade. $\mathrm{O}$ autor sugere que é necessário aplicar-se a si mesmo. Portanto, relacionar o reencontro do "eu" em um ato artístico, como discutido anteriormente, torna-se imprescindível, uma vez que o desvio do cuidado de si é um desvio de retorno ao próprio "eu", distanciando-se, assim, da experiência estética.

Nascimento (2009), seguindo a linha de Foucault (2010), relaciona o processo do cuidado de si à questão da auto-educação, onde o cuidado de si constitui-se em um exercício filosófico, uma vez que se trata de um cuidado ético-moral de si, definindo a relação de sujeito consigo mesmo, ou seja, “[...] a maneira como o sujeito se constitui como sujeito para consigo mesmo" (FOUCAULT, 2010, p.451).

Entendemos, portanto, que o primeiro passo desse sujeito - contador de história - é auto-educar-se no sentido da busca por essa 
experiência estética propiciada pela contação de história, pois, ao propor o incentivo à leitura, o sujeito deve fazer parte do universo da leitura, ocupando o papel ora de mediador, ora de próprio leitor.

Essa busca, para Nascimento (2009), corresponde a permanecer dentro do seu próprio contexto, da sua própria sociedade, conhecendo seu passado e seus mestres, entre outros, e, a partir daí, angariar meios para participar de um futuro, desenvolvendo sua prática eticamente.

\section{APONTAMENTOS SOBRE O PROGRAMA NACIONAL DA BIBLIOTECA NA ESCOLA}

No domínio da leitura, faz-se necessário explorar as múltiplas oportunidades que as obras literárias oferecem, buscando o que lhe desperta o encantamento. Trata-se, enfim, de se descobrir como leitor.

Com efeito, embora haja uma gama infinita de publicações literárias, diferenciandose em temas, suportes informacionais e formas de apresentação, ainda é possível verificar o baixo envolvimento de parte da sociedade com a leitura. Oriundos dessa realidade brasileira, que aponta índices nacionais de poucos leitores, alguns sujeitos colocados no papel de mediador de leitura ainda não são leitores.

Unindo forças, o Governo Federal promove o incentivo à leitura a partir da distribuição de exemplares literários, formando espaços de leitura nas escolas públicas por meio do Programa Nacional da Biblioteca na Escola (PNBE)

Trata-se de um programa de grande relevância social em todos os sentidos, na medida em que tem como objetivo "[...] fornecer aos estudantes e seus professores material de leitura variado para promover tanto a leitura literária, como fonte de fruição e reelaboração da realidade, quanto a leitura como instrumento de ampliação de conhecimentos [...]” (BRASIL, 2014).

Caracterizado pela diversidade e qualidade, o acervo literário, conforme podemos constatar em Brasil (2014), é composto por quatro tipos de textos: em prosa - novelas, contos, crônicas, memórias, biografias e teatro; em verso - poemas, cantigas, parlendas, adivinhas; livros de imagens e livros de histórias em quadrinhos.

No contexto de escolas públicas, o sujeito contador de histórias tem a sua disposição um rico material a ser utilizado na mediação da leitura, mas, no caminho da busca pela auto-educação, deve primeiramente fruir dessa literatura, buscando o seu reencontro com o "eu". Com efeito, o encantamento com a leitura será subsídio para tornar-se um novo leitor, apto a despertar esse encantamento pela leitura em outros sujeitos.

\section{CONSIDERAÇÕES FINAIS}

A contação de história dispõe de técnicas para sua execução, que podem e devem ser desvendadas e aplicadas pelo contador de histórias. Estas, porém, devem ser consideradas como um segundo passo, após encantamento do próprio contador de histórias. Essas técnicas poderão ajudar o contador a exprimir a história, cativando a audiência cujas emoções podem ser indissociavelmente ligadas às dos personagens da história, despertando a empatia de quem a ouve.

Dentre inumeráveis benefícios do envolvimento com a leitura, destacamos, em especial, a empatia despertada, que pode ser ferramenta importante no desenvolvimento de relações entre sujeitos do mesmo grupo social. Em última análise, essa empatia promove coesão entre as pessoas que compõem esse grupo e serve como um método valioso de passar o conhecimento para gerações futuras. Isso colabora para as relações sociais no próprio espaço de leitura, entre o mediador e a audiência, expandindo-se também para outras dimensões da escola e dos grupos sociais em que esses sujeitos - contador e ouvinte - estão inseridos.

Consideramos, em fim, que esses momentos de reflexão dos mediadores de leitura precisam ser preservados e instigados, pois a grande mudança está em cada um, o que pode levar a uma mudança significativa no todo que o envolve. A leitura é uma agente de transformação social e os espaços de leitura são destinados, em especial, às viagens ao mundo invisível da imaginação e ao acesso aos 
livros.....ah os livros, obras de arte prontos para serem explorados.

E de forma simples, sem pretensões literárias apuradas, resguardando-nos de severas críticas pela falta de apreço pela métrica, mas imbuídos da intenção de clarificar o encantamento de contar, apresentamos um versinho para que o contador possa se encantar... ou não:

Quem conta um conto?

Quem conta um conto

Se encanta...

Quem conta encanta!

Quem se encanta?
Quem um conto conta,

E nesse conto encanta...

Quem conta se encanta!

Quem ouve um conto?

Quem se encanta com o conto

E vê quem conta encantado...

Ouve um conto e fica encantado!

O sorriso, o brilho no olhar,

A expectativa, a alegria, A motivação, a sensação de prazer

Tudo se encontra no livro Que se conta!

(Eduardo Junior, 2014 - manuscrito)

\title{
TELLING STORIES AND ENCHANT IN THE SPACES OF READING
}

\begin{abstract}
Presents the storytelling as art, an aesthetic experience, as one can enchant his audience. Traverses the concept of enchantment as a state of ecstasy, noting that this state of beyond consciousness provides a return to the " $I$ " of the agent, i.e. a self-delight is the storyteller who can, first, enjoy this enchantment. Reflects on the National Plan for School Library as an enabler of books that the storyteller can/should feed it.
\end{abstract}

Keywords

Storytelling. Storyteller. Enchantment. National School Library Program.

Artigo recebido em 20/09/2014 e aceito para publicação em 29/09/2014

\section{REFERÊNCIAS}

BRASIL. Ministério da Educação. Plano Nacional Biblioteca na Escola. Disponível em:

$<$ http://portal.mec.gov.br/index.php?option=c om_content\&view $=$ article\&id=12368\&Itemi $\mathrm{d}=\overline{574}>$ Acesso em 23 jan. 2014.

FOUCAULT, Michel. A hermenêutica do sujeito: curso dado no Collége de France (1981-1982). 3.ed. São Paulo: Martins Fontes, 2010.
GRIFFERO, Tonino. Catarse. In: Cartia, Gianni; D’Angelo, Paolo (Direção).

Dicionário de estética. Lisboa: Edições 70, 2009.

NASCIMENTO, Wanderson Flor do. Entre o poder e a subjetivação, Foucault: sobre uma educação não-fascista. Trilhas Filosóficas. Ano 2, n.2, 2009. ISSN: 1984-556.

Disponível em: $<$ http://www.uern.br/outros/trilhasfilosoficas/ conteudo/N_04/II_2_art_7_Nascimento.pdf $>$ Acesso em: 21 jan. 2014. 